\title{
Le Subdray-Les Varennes
}

$n^{\circ} 068536$

Sébastien Jesset

\section{(2) OpenEdition}

Journals

Édition électronique

URL : http://journals.openedition.org/adlfi/13522

ISSN : 2114-0502

Éditeur

Ministère de la culture

Référence électronique

Sébastien Jesset, « Le Subdray-Les Varennes », ADLFI. Archéologie de la France - Informations [En ligne], Centre, mis en ligne le 10 octobre 2014, consulté le 19 avril 2019. URL : http://

journals.openedition.org/adlfi/13522

Ce document a été généré automatiquement le 19 avril 2019.

(C) Ministère de la Culture et de la Communication, CNRS 


\title{
Le Subdray-Les Varennes
}

$n^{\circ} 068536$

\author{
Sébastien Jesset
}

Lien Atlas (MCC) : http://atlas.patrimoines.culture.fr/atlas/trunk/index.php?

ap_theme=DOM_2.01.02\&ap_bbox $=2.268 ; 46.986 ; 2.340 ; 47.051$

1 Le projet d'aménagement de la mise à deux fois deux voies du tronçon de la RN 151 entre Bourges et Saint-Florent-sur-Cher est à l'origine de cette opération archéologique. L'ensemble du terrain se trouve sur un vaste plateau culminant à 152 m NGF, limité au sud par la vallée du Cher située au delà du tracé. Le sous-sol est formé par le calcaire lacustre du Jurassique ; les plis et les anfractuosités de cette couche ont été remplis par des dépôts du Tertiaire constitués d'hydroxyde granuleux pisolithique (minerai de fer en grain) alternant avec des argiles et des marnes; ils sont recouverts par une couche de calcaire grossier et lité du Tertiaire, d'une puissance stratigraphique variable. Ce minerai des formations sidérolithiques se caractérise par des gîtes irréguliers, logés dans des cavités superficielles des calcaires et d'une épaisseur variant de 0,60 à $1 \mathrm{~m}$.

2 Un diagnostic préliminaire a été effectué en janvier et février 1997:5500 m de tranchées exploratoires ont été creusées à cette occasion. La fréquence des puits de mines avortés retrouvés, et la découverte d'un puits débouchant sur une galerie a conduit le Service régional de l'archéologie à poursuivre les recherches par la mise en place d'une opération de fouille en mars 1997, qui devait permettre d'identifier le type de matériaux extraits, de caler chronologiquement cette activité, de relever dans la mesure du possible les galeries et les puits d'accès, et d'étudier l'économie générale de la mine.

Environ $50 \mathrm{~m}$ de galerie ont été explorés au cours de l'intervention. L'exploitation mise au jour est caractérisée par :

- des galeries de circulation dans lesquelles sont observés des fronts de taille (1, 2, 3 et 4). Trois d'entre elles ( 1,2 et 4 ) ont une largeur et une hauteur importante qui varie entre $2 \mathrm{~m}$ et $5 \mathrm{~m}$ de large pour une hauteur de $3 \mathrm{~m}$ environ. La galerie 3 est de dimension plus modeste (environ $1 \mathrm{~m}$ de large pour $1 \mathrm{~m}$ de haut) ; 
- des puits de descente localisés dans les galeries de circulation ;

- des galeries d'extraction associées à des caverons périphériques.

Ces différents éléments constitutifs de l'exploitation révèlent un plan assez loin du modèle d'exploitation par puits et galeries organisés sur un quadrillage orthonormé, évoqué par le règlement ministériel en date du 22 avril 1844. De même, les consignes de sécurité ne sont pas respectées : les galeries de circulation ont une largeur bien supérieure à $1 \mathrm{~m}$ et aucune trace de boisage n'a été mise en évidence. L'exploitation du gîte est marquée par les fronts de taille retrouvés en bout de galerie et les caverons. La présence de ces deux techniques d'extraction dans un même réseau est inhabituelle : les puits et caverons périphériques rayonnant de courte distance, sont utilisés dès l'Antiquité, alors que les puits et galeries le sont essentiellement dans la deuxième moitié $\mathrm{du} \mathrm{XIX}^{\mathrm{e}}$ siècle. L'existence de ces deux techniques dans un même lieu suggère soit une période de transition (adaptation des techniques), soit plus probablement la superposition de plusieurs exploitations diachroniques ou d'extension progressive du réseau.

5 A l'aide des sources documentaires, il a été possible de dater du milieu du XIX ${ }^{\mathrm{e}}$ siècle le dépilage mis au jour. D'autre part l'étude des galeries a permis de mettre en évidence la gestion de la mine avec vraisemblablement la superposition de plusieurs petites exploitations par puits et galeries, et une possible exploitation par cavage à bouche. Les caractéristiques soulignées permettent d'entrevoir une extraction manuelle de blocs et de fragments plus réduits d'argile à pisolite, pratiquée à l'aide de piochons ou de pics. Enfin, la confrontation du plan obtenu avec des modèles de mines fournis par les sources documentaires conforte l'idée d'une pratique désordonnée en cours de mutation. Il semble en effet qu'il y ait une rupture entre l'exploitation par puits et caverons et l'exploitation par puits et galeries. Même si le modèle théorique n'est pas encore respecté, même si les consignes de sécurité ne sont pas appliquées, il semble bien qu'il s'agit d'une exploitation qui appartient à cette période de mutation. Les preuves en sont les différentes techniques adoptées et les prémices de gestion soulignées plus avant.

\section{INDEX}

Index chronologique : Antiquité, ép. contemporaine, XIXe siècle apr. J.-C.

Index géographique : Centre, Cher (18), Le Subdray, Les Varennes

operation Sauvetage urgent (SU)

Mots-clés : puits, galerie, caverons, mine 